\title{
International Channels of Distribution: A Classification System for Analyzing Research Studies
}

Prescott C. Ensign, University of Ottawa

ABSTRACT: This paper presents a systematic method for classifying research on international channels of distribution. It is used to examine 79 articles published during an 18-year period (1988-2005). Based on content analysis, each article is classified by its primary research framework. Two frameworks are identified: (1) structural - based on the economic and organizational aspects of international channels of distribution; and (2) behavioral - based on the exchange relationship between channel members from different national environments. This simple organizing system offers a comprehensive way to analyze scholarship that has emerged in the field. For managers, it can bring the theoretical and practical developments together in an understandable fashion as they seek to interpret and apply research findings. For scholars, it may bring focus to an increasingly complex area of international business and guide future research efforts.

\section{INTRODUCTION}

Distribution channels are among the most highly differentiated aspects of international marketing. Marketing channel decisions involve supply chain strategy at the policy level and channel management at the operations level. The complexity of these decisions is increased by widely different social, cultural, economic, and political patterns. While analysis of domestic channels and the concepts embodied in channel management theory may be applicable in an international setting, generalizations about international channels of distribution can be deceptive due to the extent of country-to-country differences (Stern and El-Ansary 1992). The literature on domestic channel practices does not provide sufficient answers for the conduct of activities across borders (Seifert and Ford 1989).

Prescott C. Ensign is an Assistant Professor in the Telfer School of Management at the University of Ottawa, Ontario, Canada. His research interests include internationalization of high-growth firms, firm entry strategies in emerging markets: and collaboration across physical, cultural, social, organizational, and technological distance.

E-mail: ensign@telfer.uottawa.ca

Acknowledgements: The author owes an intellectual debt to Professor John K. Ryans. Jr. and appreciates his guidance and encouragement. Thanks are also due to David A. Griffith for helpful discussions and comments. Support as a Fulbright Scholar from the Foundation for Educational Exchange between Canada and the US, Institute of International Education, and J. M. Smucker Company is gratefully recognized. This work has benefited by funding received from the Social Sciences and Humanities Research Council of Canada. 
Given the strategic significance and complexity of distribution channels in international business, it is worthwhile to scrutinize prior scholarship in this important area. In an effort to consolidate our understanding and to move the research agenda forward, this paper considers:

- What issues have received attention (which ones should)?

- What approaches and methods are used?

- Is there a wholistic way to understand and categorize research efforts?

- What lessons and insights can be shared with practitioners?

$\pi$

Based on a review of the literature, a gap has been identified: there is no single classification system for understanding research efforts. Proposed is a comprehensive system for sorting research on international channels of distribution. This hierarchical taxonomy is employed to analyze 79 academic articles published during an 18-year period (1988-2005). Prior studies have (1) generated a wealth of knowledge. In ᄃ this paper, accumulated research is synthesized and it is hoped that this classification system will provide a basis for future research efforts and assist marketing managers as they seek to interpret and apply scholarly findings.

\section{Analysis of Existing Research}

A survey of recent literature (1988-2005) was undertaken to identify studies on international channels of distribution. An initial search was made using several electronic databases (e.g., Business Source Premier and ProQuest). Journals related to international marketing, international business, marketing, and marketing research were also reviewed in an attempt to make the search as complete as possible. The final selection of articles was based on content analysis. An article was selected if it focused on some aspect relevant to the development and/or maintenance of interorganizational channels of international distribution. A total of 79 articles were selected for inclusion in the present study. Although no claim is made that this was an exhaustive search, it provides evidence to support the view suggested by some scholars that there are a limited number of studies on international channels of distribution (Cabaniss 1991; Griffith and Ryans 1995; Rosson and Ford 1980; Samiee 1993; Seifert and Ford 1989). Though an increase in the formation of channel partnerships in the 1990s has been indicated (Buzzell and Ortmeyer 1995), the level of scholarship on the subject has not kept pace. Compare this attention with that given in the international business literature to joint ventures and alliances - something in which far fewer firms engage, but hundreds of articles are published.

Each article was first classified by primary research framework. Two research frameworks are used in this study. These two general approaches are derived from a dichotomy arising 
in the literature; chiefly the economic, physical, technical 'hard' side versus the social, psychological, 'soft' side. Drawing from Stern and colleagues $(1969,1980$, and 1992) these are conceptualized as:

(1) structural framework - based on the economic and organizational aspects of international channels of distribution; or

(2) behavioral framework - based on the exchange relationship between channel members from different national environments.

An integrative understanding put forth in this paper builds on the view espoused by Stern and El-Ansary (1992: 38) - "the marketing channel is a complex technical and behavioral system." It also is complementary to Stern and Reve's (1980: 52) "analysis of distribution channels which encompasses both economic and sociopolitical determinants of channel member behavior." The dichotomy proposed in this paper is essentially a return to Stern's (1969) book Distribution Channels: Behavioral Dimensions that affirms these frameworks.

Articles classified into the two research frameworks are further divided by approach taken. Those with a structural framework are further classified by: (1) developmental/ evolutionary approach, (2) transaction cost approach, or (3) comparative approach. Those with a behavioral framework are further classified by: (1) relational approach; (2) crosscultural approach; or (3) prescriptive approach. These approaches reflect the specific goals of the individual studies. The approaches were culled from the literature prior to classification of the articles. While taken as discrete categories, there can be a degree of overlap in approaches.

That is an article may include elements that examine relational activity (relationship between manufacturer and intermediary) as well as crosscultural. Several articles purposefully cross boundaries. It is evident that a few of the early as well as the most recent research efforts fall into more than one domain.

Two independent coders - one unrelated to this paper (not the author) - both familiar with the literature were used to place articles according to structural framework and particular approach. Intercoder reliability was high - with few discrepancies in interpretation resolved carefully. Several articles were excluded in cases where agreement could not be reached. Distinctive or notable research methods employed are discussed for the structural approach as well as the behavioral approach. The 79 articles reviewed and classified are presented in Table 1.

\section{STRUCTURAL FRAMEWORK}

Research classified as having a structural framework focuses on specific aspects of channel design related to economic structure - the transactional form existing in the channel - and/or the organizational structure - the type and number of institutions in the channel (Leonidou 1989: 17). The 


\section{TABLE I: A CLASSIFICATION SYSTEM FOR ANALYZING RESEARCH STUDIES}

\section{STRUCTURAL FRAMEWORK}

Developmental Approach

Bello, Urban, and Verhage 1991

Bello, Verhage, and Bronislaw 1989

Chen and Huang 2004

(1) Chu 1989

Gadde 1993

Griffith, Chandra, and Fealey 2005

Griffith and Ryans 1995

(d) Howard and Maskulka 1988

(1) Mazzoleni 1998
Ramaseshan and Patton 1994
Seifert and Ford 1989

Terpstra and Yu 1990

$\infty$

$\boldsymbol{\infty}$

(1)

common emphasis is on the issue of distribution choice (alternative channel structure) and efficiency aspects (cost) of the distribution channel. In addition to the effects of behavioral processes on international channels, economic/competitive, sociocultural, technological, and legal/political factors influence

\section{BEHAVIORAL FRAMEWORK}

Relational Approach

Balabanis 1998, 2005

Bello and Gilliland 1997

Bello, Chelariu, and Zhang 2003

Cavusgil, Deligonul, and Zhang 2004

Frazier. Gill, and Kale 1989

Karunaratna and Johnson 1996

Katsikeas and Piercy 1991

Kim 2003

Leonidou 1989

Liu and Wang 1999

Moore 1991, 1992

Paswan and Young 1999

Rose and Shoham 2004

Weich and Wilkinson 2005

Cross-Cultural Approach

Bandyopadhyay, Robicheau, and Hill 1994

Borin, Van Vranken, and Farris 1991

Geyskens, Steenkamp, Scheer, and Kumar 1996 Johnson, Sakano. Cote, and Onzo 1993

Johnson, Sakano, and Onzo 1990

Kale and Mcintyre 1991

Llanes and Melgar 1993

Marshall 2003

Mehta, Larsen, Rosenbloom. Mazur, and Polsa 2001

Mehta, Larsen, Rosenbloom, and Ganitsky 2006

Rosenbloom and Larsen 2003

Yavas 1998

Yoon, Morash, Cooper, and Clinton 1996

\section{Prescriptive Approach}

Cavusgil and Kirpalani 1993

Fram 1992

Grunert, Jeppesen, Jespersen, Sonne, Hansen,

Tronsen, and Young 2005

Keitt 1990

Mehta, Larsen, and Rosenbloom 1996

Michael 1998

Rosenbloom 1990

Shipley, Cook, and Barnett 1989

Thomas and Wilkinson 2005

Weigand 1989, 1991

Zhang. Cavusgil, and Roath 2003

distribution (Rosenbloom 1999: 526).

While channel design and selection provide a common framework for structuralist authors, they differ on what should be considered in evaluating and choosing alternative channel intermediaries as well as on the issue of vertical integration. In the second level of this hierarchy three 
approaches are identified to describe these differences: developmental/ evolutionary approach, transaction cost approach, and comparative approach.

\section{Developmental/Evolutionary Approach}

Like other socioeconomic phenomenon, international channels of distribution change over time. Some scholars focus on the stages of a firm's internationalization and its channel management. This implies that the structure and type of international channels of distribution follow a pattern as a firm moves from using intermediaries to functional absorption to direct exporting(Terpstra and Yu 1990). Others consider this to be an incremental process rather than discrete stages that develop over time (Howard and Maskulka 1988). Griffith and Ryans (1995) note that global marketing channels can evolve naturally, pointing out that transaction cost concerns has been dramatic-often overshadowing other concerns. They posit that the preoccupation with transaction costs has been detrimental for both practice and scholarship. For the practitioner charged with responsibility for Inanaging marketing channels, he or she should be cognizant of the natural progression.

Bello and Verhage (1989), Chen and Huang (2004), and Howard and Maskulka (1988) take a developmental approach to describe the way firms enter international markets and how this develops over time. Bello and Verhage (1989) combine export stage and transaction cost analysis to examine the structural changes that occur as firms move through various phases. Firms that manufacture industrial products, however, do not necessarily undergo all steps of the internationalization process (Bello, Urban, and Verhage 1991). Chu (1989) describes this as a process of learning-by-doing, which can lead to vertical integration of distribution activities. A developmental approach is also evident in the work of Seifert and Ford (1989). They survey industrial firms to determine the choice of foreign-based (direct) or domestic-based (indirect) distribution channels and level of satisfaction with the distribution channel chosen. Again. the administrator overseeing international distribution channels should be aware that there may be no single correct trajectory; experience and learning play an important role. The notion of equifinality suggests that there may be an array of decisions' choices that lead to the same result.

Chen and Huang (2004) examine Taiwanese small and medium-sized enterprises as they cultivate global marketing activities: setting up, establishing, developing, and building are all descriptors used in their analysis. These firms overcome barriers as they progress through stages of internationalization or else defy the typical sequence and begin as global enterprises ('born global'). In a rebuttal to the driving force of international strategy - transaction cost efficiencies - Griffith, Chandra, and Fealey (2005) explore 'natural' channels of distribution; those that 
have evolved. They report on 22 indepth interviews of global marketing managers in the emerging market of India and isolate various factors (internal and external) that affect the course of channel development.

Gadde (1993) sees distribution networks as evolutionary-developing through time as a result of the actions of network participants and their efforts to exert control. The concepts of coordination and mobilization are used "in an analysis of evolution in distribution networks" (Gadde 1993: 43). In a historical study, Mazzonleni (1998: 420) found that "a network of manufacturer-overseas distributor relationships evolved over time as pervasive asymmetric information problems were resolved." $\mathrm{He}$ also found evidence that social norms could be used to combat agency concerns. This suggests that channel relationships require work but that maturation and resolution cannot be forced. Interaction among actors is important, even time plays a role in healing relationships, assuaging contentions, and ironing out thorny issues.

\section{Transaction Cost Approach}

The transaction cost approach - based on the work of Coase (1937) and Williamson $(1979,1981)-$ provides a coherent framework for investigating determinants of vertical integration. This approach - a combination of organizational theory, economics, and modern contract law - is an explanation for why managers select different channel structures to coordinate the exchange (Dwyer and Oh 1988). The transaction cost approach suggests that cost minimization can justify these structural decisions. Manufacturing firms internalize transactions (integrate forward) to reduce costs (Klein and Roth 1993). A firm's optimal channel structure should reflect both the volume of sales involved and the vulnerability of the firm to opportunistic behaviors by external intermediaries (Klein 1991; Klein, Frazier, and Roth 1990; Klein and Roth 1990, 1993).

Rialp, Axinn, and Thach (2002) examine the channel integration decision of over 2,000 Spanish firms engaged in exporting. They find strong evidence of internalizing operations. Their research also delves into various "institutional arrangements for accomplishing international distribution" (Rialp, Axinn, and Thach 2002: 134). Studying small knowledge-intensive firms, McNaughton (2002) finds that multiple distribution channels are often chosen to serve foreign markets and that integrated modes are often preferred for international channels as they facilitate protection of intellectual assets and provide high levels of customer service and support. McNaughton (2002: 190) develops and tests a "transaction cost analysis model of channel choice."

Transaction costs are contingent on the firm's unique circumstances. Empirical work by Bergen, Heide, and Dutta (1998), Kim and Daniels (1991), Klein, Frazier, and Roth (1990), and Harvey and Novicec (2002) suggest that a product's 
transaction-specific assets are a key factor in explaining the selection of a given integrated channel. Klein and Roth (1990) provide an exploratory paradigm based on transaction cost analysis to examine the effect that experience and psychic-distance have on determining the selection of an export channel structure. Klein and Roth (1993) also relate lower transaction costs to satisfaction with channels. Klein and Roth (1990) support the view that when markets operate efficiently, opportunistic expectations will be bargained away. For the marketing manager, every situation has its own particular conditions; analysis and calculation may be relied upon, though not at the expense of or in the absence of other considerations.

\section{Comparative Approach}

The comparative approach to the study of international marketing channels involves identifying, classifying, measuring, and interpreting the commonalities and differences in structures and patterns of distribution between nations (Boddewyn 1981). In terms of overall perspective, structuralists maintain that a standardized global marketing strategy does not apply to distribution strategy in foreign markets. In Rosenbloom and Larsen's (1991) view, a common global strategy does not provide marketing managers with enough knowledge and insight about multi-domestic channels of distribution. A customized, adaptive, and situational view is needed to provide for differences across national environments. Cavusgil and Zou (1994: 5) evaluate channels of distribution and export strategy in general along the "standardizationadaptation continuum" and find that they are a function of: internal forces - consisting of characteristics of the firm and product; and external forces - consisting of characteristics of the industry and market. Myers (1999) draws attention to the fact that parallel channels of distribution or gray markets are a growing phenomenon. While the calculus may not be as clear for evaluating transactions, such attention is no less important in comparing and controlling modes of exchange.

Kim and Oh (2002) survey international distributors in the US and Japan and find the influence of institutional factors vary according to channel context. McNaughton and Bell (2000) explore channel switching by small knowledgeintensive firms. They weave transaction cost considerations with an evolutionary approach: "the domestics channel is frequently extended into a foreign market to gain economies ... managers need to be aware of the momentum created by domestic channels" (McNaughton and Bell 2000: 24).

Although the present interest in global supply chain management highlights the importance of the function, many elements of the marketing mix are not suited to a single, global marketing strategy. The research work of structuralists especially those using a comparative analysis approach - suggests that 
distribution strategies must be developed for the specific situation in each national market. Since structuralists - and especially those that take a comparative approach tend to focus on foreign market entry, there is always the possibility of an overemphasis on channel differences among nations.

\section{Structuralist Framework}

\section{Research Methods}

In reviewing the methods used in research having a structural framework, some general observations can be made. One study (Terpstra and Yu 1990) is based on anecdotal case studies. Most of the 38 structuralist studies in Table 1 are large-sample empirical investigations use data obtained in survey questionnaires to test hypotheses. Howard and Maskulka (1988) survey export management companies to determine their desire to participate in an export trading company. Studies by: Bello, Urban, and Verhage (1991); Bello and Verhage (1989); Klein, Frazier, and Roth (1990); and Klein and Roth (1993) - were designed to test hypotheses related

$\boldsymbol{D}$ to channel structure selection and ᄃ satisfaction. The methods in these studies were similar. A representative sample of manufacturers and channel intermediaries was selected; a questionnaire - with responses presented on a Likert-type scale - was used to measure perceptions and preferences.

From a methodological standpoint, the study by Kim and Daniels (1991) employs a somewhat different research design. Their study examines marketing channel decisions. The sample included both foreign manufacturing subsidiaries and domestic firms in the US market. By selecting foreign and domestic firms operating in the same market, the sample includes both quasi control and experimental groups. The size of the sample was also large enough to test national and multinational global standardization strategies. In general, this research design provides better information on channel selection than that which can be obtained from research on a single group.

Shin, Hahn, and Park (1996) test hypotheses based on predictions from game theory. They evaluate market dynamics using: competition intensity, product substitutability, market predictability, and number of competitors. In a thorough study of the factors predicting channel integration, Aulakh and Kotabe (1997) utilize an eclectic approach. Work by Ekeledo and Sivakumar (1998) and Erramilli and Rao (1993) are notable as the focus is service firms - largely an ignored area. The research of Kim, Nugent, and Yhee (1997) and Osborne (1996) contributes to the literature on small- to medium-sized firms. Interest in smaller, younger, more entrepreneurial international firms seems to be generating increased attention (e.g, Chen and Huang 2004, McNaughton 2002, McNaughton and Bell 2000, Rialp, Axinn, and Thach 2002). A glance through the list of authors in Table 1 reveals that quite a few scholars have a growing body of work in this field. Their devotion to 
the topic points to an ongoing research design that systematically addresses a number of issues often from multiple perspectives (institutional vs. interpersonal; in-depth interviews vs. large sample survey).

\section{BEHAVIORAL FRAMEWORK}

Research classified as having a behavioral framework focuses on the interaction between channel members and how that exchange is affected by interpersonal dynamics and environmental factors and intrachannel operating practices. In this research the emphasis is on the relationship between different channel levels that are interdependent in nature and embedded in the act of exchange. The primary focus is on the channel member relationship - the dynamics of interpersonal behavior as filtered by cultural differences. As Seifert and Ford (1989: 15) state, "the positive or negative interactions in such a relationship can result from personality, experience, and ethnic or cultural phenomena." This is in contrast to research classified as having a structural framework that has as its primary focus the concepts such as cost analysis, channel design, or channel integration.

Studies classified as having a behavioral framework generally rely on the measurement of perceptual phenomena and the development of practitioner-based constructs. They address the complex nature of the underlying behavioral dimensions influencing the domestic manufacturer and foreign intermediary relationship. The focus is on the management of ongoing dyadic channel relationships rather than on the structure of the channel (Klein, Frazier, and Roth 1990). The emphasis is typically on the interpersonal experiences of the channel member that are likely to shape the channel relationship. These relationships are based on familiarity and trust that result from repeated business and social interactions as well as on personal conflicts that result from personality or cultural differences (Ford 1980). Gaski (1984) notes that power and conflict play a prominent role in channels of distribution. Frazier (1999: 226-227) indicates that "intrachannel conflict and its impact on long-term channel relationships is often confused.... Power remains a misunderstood construct in channels-of-distribution research. Confusion still exists among the power, communication, and control constructs in both a conceptual and operational sense." Table 2 provides a strong guide or useful basis for the marketing manager to handle channel partners.

Once channels have been established there is no guarantee that they willoperate successfully. Realistic, cost-effective implementation, and first-rate execution depend on a firm's management techniques and mechanisms (Stern and El-Ansary 1992: 267). Most behavioral research, regardless of approach, examines interpersonal attributes (often on a functional/dysfunctional continuum) that are characteristic of specific channel relationships to determine, for example, how a higher degree of interorganizational coordination 
can be achieved within a particular channel relationship. "Shifts in the balance of channel power" and "changing strategic priorities" have resulted in channels becoming "dynamic webs" (Anderson, Day, and Rangan 1997: 59). Table 2 lists the attributes used to measure, describe,

(1) or predict specific behavior. The list is derived from factors identified in the 41 behavioral framework articles analyzed in this study.

The behavioral attributes recorded in Table 2 emphasize that channel relationships are extremely complex. Although behavioralists share a common overarching framework, they take different approaches as they try to isolate the role played by personality, experience, culture, and ethnicity. From the behavioral branch in the taxonomy the second level in the hierarchy divides research under this framework into three types: relational approach, crosscultural approach, and prescriptive approach.

\section{Relational Approach}

Research classified as taking a relational approach focuses on the satisfaction with the relationship rather than on cultural factors in the relationship or aspects of structural change implemented by manufacturers (Moore 1991). In general, interactions between manufacturer and intermediary are understood to be a multidimensional phenomenon along a heterogeneous transaction continuum. Those who study the long-term development of these relationships are classified as taking a relational approach within a behavioral framework (Anderson and Narus 1990; Balabanis 2005; Dwyer, Schurr, and Oh 1987; Ganesan 1993, 1994; Rose and Shoham 2004). Research that examines this as a discrete or transaction-specific phenomenon takes a transaction cost approach within the structuralist framework (Heide and John 1988, 1990, 1992).

The primary purpose of research that takes a relational approach is to look at the interaction constructs (e.g., dependence, reciprocal action, goal congruence, etc.) in distribution channel relationships. Such research considers that both channel members are actively involved in the international trading equation. The emphasis is on the behavioral complexities of their working relationship and how these affect their operating performance (Leonidou 1989). Based on the current interest in relationship marketing, it is evident that the management of relationships is becoming a major paradigm in marketing channels research and practice (Heide 1994; Long 2003; Morgan and Hunt 1994).

In contrast to interorganizational relationships, Rose and Shoham (2004: 942) find that between manufacturers and their international channels of distribution (an interorganizational relationship), task or functional conflict does not build the relationship but reduces "the quality of strategy employed, reducing performance." Kim (2003) studies interdependence of channel members and distributors. His work also contributes to the 


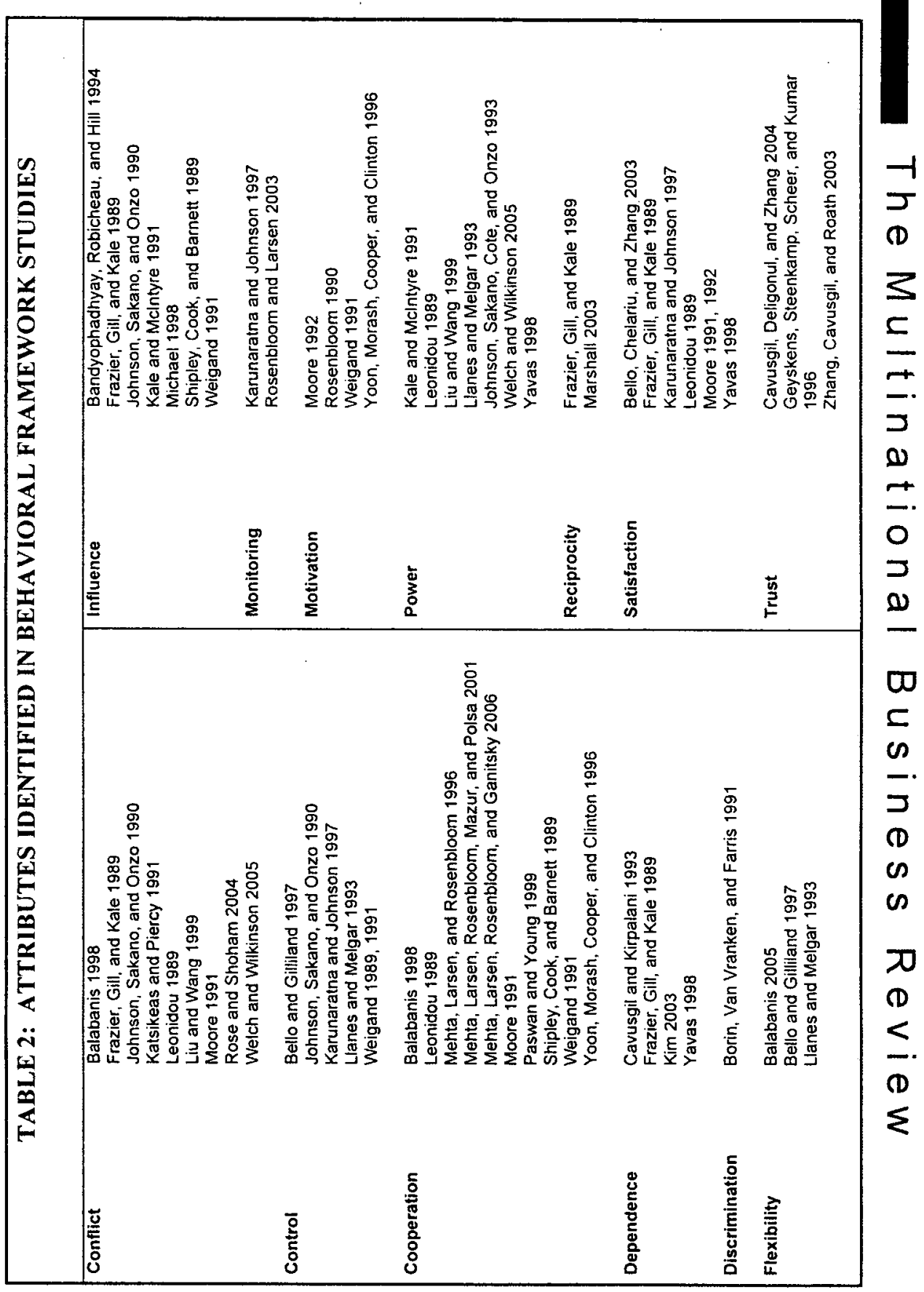

literature by examining industrial

Moore (1991) examines products (rather than consumer relationship states between goods) and does so via a multi- manufacturers (Great Britain) country study of the US and Japan. and overseas intermediaries 
(West Germany). This study is quite different from those that examine the dimensions of time - the length, duration, or specific moment (initiation, implementation, renewal, review, termination, etc.) - in channel member relations. Using Ford and Rossen's (1982) (1) method, Moore (1991) suggests the

following relationship states: new, growing, troubled, static, and inert or declining. Critical understanding and knowledge of subtleties in relationships is growing. Considering the state of a channel relationship is worthwhile, particularly in reference to what it could be. There is evidence to suggest devoting time to such reflection is warranted (Madhok and Tallman 1998).

These states seem to be descriptive of relational conditions and market position rather than developmental in a lineal or stages sense. This underscores that there exist categories or descriptions for types of behavioral relationships between manufacturers and foreign distributors that may even reflect their economic success. As Moore (1991) points out, the length of time that a manufacturer

(1) and foreign distributor have worked

ᄃ together is primarily a measure of the level of satisfaction with the relationship. In another study, Moore (1992) expanded his work to include distributor motivation and the perceptions by both channel members of sales trends and satisfaction.

Welch and Wilkinson (2005) used a network theoretic approach to investigate a single critical case involving Australian and Japanese firms. This network analysis sheds further light on power and conflict. Moving beyond competing perspectives, Cavusgil, Deligonul, and Zhang (2004) attempt to tease out contingencies in international channel relationships. They employ structural equation modeling to explore interaction effects and moderating effects. Their empirical work starts with a recognition that prior studies were often at odds with one another because of their efforts to reveal either/or factors, when the reality is more nuanced than that. For example, Cavusgil, Deligonul, and Zhang (2004: 7) find that trust and formal contracts are not necessarily competing alternatives; under certain conditions of opportunism one may be preferred, but often both may be employed - "trust makes the relationship function and contracts institute and legitimize it."

Frazier, Gill, and Kale (1989) and Leonidou (1989) build on the work of El-Ansary and Stern (1972), which deals with power in channel relationships. Leonidou (1989) uses the term atmosphere in referring to the interdependence that governs the working relationship between Cypriot exporters and British importers. The success or failure of an exporter based in a developing country is largely associated with how behavioral aspects of the relationship with the foreign importer are managed. Katsikeas and Piercy (1991) follow Leonidou's research on the character of conflict in the relationship between the developing country indigenous manufacturer (Greece) 
and the developed country importer (Great Britain). Their study reports a prevalence of substantial perceptual differences between the two parties in the exporter-importer dyads although there was no systematic character to these.

An empirical study by Frazier, Gill, and Kale (1989) centers on dependence and reciprocal actions in a distribution channel. Their study on the use of influence strategies in channel relationships focuses on industrial manufacturers and dealers in a developing country (India). They report that a dealer's need to maintain a channel relationship in a seller's market is primarily driven by manufacturer contributions to sales and profit levels. They argue that this reciprocal action may be contingent on the cultural context.

\section{Cross-Cultural Approach}

Research that takes a crosscultural approach has as its primary focus the cultural context of foreign channel member behavior. Such investigation looks for evidence of differences in channel member relationships by country. Empirical studies classified as taking this approach also provide information on how various distribution principles and practices operate in different national environments.

Kale and McIntyre (1991) test 19 propositions based on Hofstede's (1984) four dimensions of culture (individualism, power distance, uncertainty avoidance, and masculinity). Their research suggests that national culture has a systematic impact on behavioral relationships within distribution channels and that this phenomenon can be determined, known, and tested empirically. The results are based on 60 in-depth interviews in five different nations. Yoon et al. (1996: 3) "compare channel integration approaches, including strategic alliances, used by approximately 2,000 firms in the Pacific Basin countries of Australia, Japan and Korea as well as the US." Mehta et al. (2001) examine leadership styles in the US, Finland, and Poland, finding that "using leadership styles to foster cooperation among channel members across different national cultures on a standardized basis is not an appropriate channel strategy." Channel alliances between US exporters and their foreign distributor partners are hampered by cultural differences; cultural distance leads to lower levels of trust, commitment, and cooperation (Mehta et al. 2006: 156).

Johnson, Sakano, and Onzo (1990) draw on the ideas of Frazier, Gill, and Kale (1989) as well as others to develop a conceptualization of control, influence, and conflict. They empirically examine USJapanese behavioral relationships in the marketing channel. Johnson et al. (1993) look at the exercise of power in US-Japanese interfirm distribution channel relationships. Rosenbloom and Larsen (2003) extend cultural distance to the context of international business-to-business e-commerce marketing channels. "Findings show that there is a relationship between culture and channel communication" 
(Rosenbloom and Larsen 2003: 309).

Llanes and Melgar (1993) look at behavioral issues in exporterimporter channel relationships. They

3 focus on the cross-cultural context

() between domestic (Filipino) exporters and foreign importers. Borin, Van

() Vranken, and Farris (1991) examine

D goods. Their findings do not support

(1) the claim that channel discrimination

ᄃ exists, at least not for those products

is examined in their study. As they note, however, equal treatment of comparable domestic and foreign products by the channel does not ensure a comparable market share.

त)

\section{Prescriptive Approach}

Research described as taking a prescriptive approach within the behavioral framework focuses primarily on the operating practices (often 'best practices'), procedures, and principles that characterize successful exporters. Many of these 12 articles in Table 1 deal with day-to-day channel operations in a

(1) pragmatic way. This research forms a ᄃ practitioner-driven approach to gilide $\vdash$ managers in directing their channel relationships.

Shipley, Cook, and Barnett (1989) suggest that there are a limited number of empirical studies on how manufacturers create, develop, and maintain effective and profitable relationships with their foreign distributors. The literature reviewed in this study confirms their observation. The work of Keitt (1990), Rosenbloom (1990), Thomas and Wilkinson (2005), and Weigand (1991) is primarily informational, descriptive, and "how to" in style. Keitt (1990) writes from the standpoint of providing assistance to US firms. His study addresses the issue of channel relationships and the most common mistakes when selecting a foreign distributor. Fram (1992) - citing Keitt and exploring some of these pitfalls - develops an exploratory study on the selection of international distributors.

Weigand $(1989,1991)$ focused on parallel import channels and re-importing (gray marketing), a tangential - though growing - aspect of international marketing channels. Weigand (1991: 56) notes that the use of unauthorized marketing channels is, at least in part, due to the opportunistic (deceitful) intermediaries who demonstrate "perfidious behavior" and discriminatory pricing by monopolistic manufacturers. Weigand (1991) cites several well-known legal cases involving parallel importers such as K-mart Corporation. Parallel channels can be utilized to supplement authorized distribution channels (Michael 1998). Based on four case studies, Grunert et al. (2005: 428) find that market orientation in the value chain is and should be related to market factors, nature of relationship, regulations, and mental models of decision makers.

Rosenbloom (1990) examines how to motivate a foreign distributor, develop good communications, be fair and reasonable by their standards, 
and be mutually committed to a continuing relationship. He notes that many environmental and cultural customs and practices affect the international marketing channel relationship. Here again, broad empirical investigation is needed since anecdotal information is not a sufficient basis from which to build a model that moves beyond intuitive, practitioner-defined prescriptive statements.

Thomas and Wilkinson (2005: 125) note that US marketing managers accustomed to ceding control in domestic distribution need to know that in high-growth emerging markets, distribution channels are malleable - they should "shape and mold the way distribution takes place."

\section{Behavioralist Framework \\ Research Methods}

Though Gaski (1984: 9) illuminated "many problems with the empirical work done in the area, both methodological and conceptual", it appears that synthesis is yet elusive. Research employing a behavioral framework is primarily exploratory and foundational in nature. This is especially evident in the works of Borin, Van Vranken, and Farris (1991), Fram (1992), Kale and McIntyre (1991), and Shipley, Cook, and Barnett (1989). Though more recent and with more sophisticated techniques (cluster analysis), research by Balabanis (2005) is nonetheless exploratory.

Studies of manufacturer and intermediary relationships attempt to identify and explore specific aspects of this interaction or exchange. Cavusgil, Deligonul, and Zhang (2004), Frazier, Gill, and Kale (1989), Johnson et al. (1993), Katsikeas and Piercy (1991), Llanes and Melgar (1993), and Zhang, Cavusgil, and Roath (2003) offer empirical insights into behavioral relationships. Although behavioralists do not explicitly label their research exploratory, this is often suggested in the conclusions. Frazier and Antia (1995: 321) point out that there are "limitations of transaction cost analysis and agency theory" and indicate that "qualitative research is urgently needed to sort out theoretical difficulties in the channels area." Cavusgil and Kirpalani's (1993) "findings reveal that factors responsible for international commercial success are different for small and large firms."

The importance of this body of work lies in the fact that each study contributes to building a conceptual understanding of channel member behavior, interactions, and relationships. As Kale and McIntyre (1991: 33) state, "with regard to behavioral relationships within distribution channels, a general consensus exists among researchers that a generalizable theory of the exchange process within channels can be achieved only by conducting studies of different countries, cultures, and industries." In a study of 290 manufacturers who use foreign distributors Bello, Chelariu, and Zhang (2003) examine antecedent channel conditions that influence relational exchanges. They present a very complete causal model of an 
international channel relationship. The procedure for conducting the research was quite rigorous; 20 in-depth interviews led to a mailed questionnaire pre-test $(n=100)$ and finally a mailed survey (290 usable responses, $72 \%$ return rate). Bello and colleagues pursuit of understanding international distribution channels implies the phenomenon is complex. In their 2003 work, they suggest future

$\infty$

()

(1) e.g., Katsikeas and Piercy (1991) using unmatched Greek exporters and British importers and Leonidou (1989) using unnatched Cypriot exporters and British importers. Llanes and Melgar (1993) studied exporters from the Philippines and importers from four regional groups (Asia, Europe, Australia, and the US) and then expanded to crosscultural issues based on the studies of Katsikeas and Piercy (1991) and Leonidou (1989). Frazier, Gill, and Kale (1989) and Paswan and Young (1999) studied manufacturers and distributors in India to test their conceptual framework. Moore (1991, 1992) studied unmatched British manufacturers and West German agent distributors but no specific hypotheses were tested. Shipley, Cook, and Barnett (1989) conducted interviews of British companies with overseas distributors in an effort to develop a conceptual framework.

Some authors (Borin, Van Vranken, and Farris 1991; Johnson et al. 1993; Johnson, Sakano, and Onzo 1990; Kim 2003; Welch and Wilkinson 2005) studied Japanese distributors and tested hypotheses. Borin, Van Vranken, and Farris (1991) used a unique approach to collect data and evaluate (code) responses. Photographs were taken in 131 retail stores of six merchandise variables to test the discrimination in merchandising support that a specific consumer good (shampoo) receives when foreign brands are compared to domestic brands. They coded the photographs as responses by 131 retailers to the six merchandise variables. This provided data for statistical analysis, t-tests, and frequency distributions.

Fram (1992) used a different methodological approach. In an exploratory study of how fourteen industrial manufacturers select international distributors, Fram used a two-phase Delphi method. Responses on 44 actions were grouped into four major areas for statistical presentation in frequency charts. Fram suggests that the data generated from such a Delphi method provide a good foundation for the development of 
hypotheses that can then be tested on a larger population. Using a scenario-based survey Marshall (2003) examined interactive decisionmaking of US and Peruvian export managers. With nearly 200 usable responses, this technique of getting responses to fictitious but realistic sequences of events, he was able to systematically map out the decision process under a specified context while permitting variance in items of interest.

\section{CONCLUSION}

The classification system proposed in this paper is a comprehensive way for scholars and practitioners to analyze and appreciate research studies on international channels of distribution. It can be used to identify both the major focus (primary framework) and the specific emphasis (approach) in research studies. Studies that fall under the structural framework umbrella are described as taking a developmental/evolutionary approach, transaction cost approach, or comparative approach. Research utilizing a behavioral framework may take a relational approach, crosscultural approach, or prescriptive approach. This typology can certainly be used to design future research on international marketing channels. Classification schemes can be an extremely useful component for advancing knowledge exploration and helpful for hypothesis formulation. Frazier (1999: 226) indicates that "we have barely touched the surface of all the managerial issues that need to be addressed. ... many issues of managerial importance relating to the organization and management of channels of distribution have received no attention in empirical research."

As noted in this paper, there are a number of questions and issues related to research on international marketing channels. Some of these were raised in the literature; others became apparent with the classification of studies being reviewed. Some scholars consider international channels as a sub-set of theoretical work on marketing channels. Others view international distribution channels as a separate field. Although they share some foundational concepts and have terminology in common, there are many differences as well. Similarities seem to be more evident in structural aspects whereas evidence of divergence is greater in behavioral aspects.

The classification system advocated in this paper helps in recognizing commonalities and differences in international and domestic channels of distribution. A comparison of research efforts that use different frameworks and approaches also reveals a number of interesting developments in channel research. Empirical studies that take a transaction cost approach, for example, often use more sophisticated techniques and methods. This is particularly evident in studies that examine vertical integration in various national markets. Studies that place an emphasis on behavioral constructs in the domestic manufacturer and foreign distributor relationship often use theories and methods from a number 
of disciplines. This is particularly evident in studies dealing with crosscultural differences. The question remains whether these frameworks and approaches will grow further apart or if they can be combined into a single eclectic framework with an integrated approach (Hill, Hwang, and Kim 1990).

For a firm engaged in international sales, the selection and management of marketing channels is a key strategic () area in the marketing mix. Based on (1) the review and classification of current c research, there are a number of studies - that add to our comprehension of the structural and behavioral aspects of the manufacturer and distributor relationship. These studies - a combination of theoretical, empirical, and practitioner-focused efforts-make a major contribution by providing a conceptual framework from which to meaningfully grasp international channels of distribution.

A diligent examination of the literature reveals that research efforts have been expanding. As scholars have noted, relative to other topics, there are a limited number of studies devoted to international channels of distribution. There exists a need for more systematic and rigorous empirical studies that test emerging constructs. Scholars conducting marketing channel research in the international domain already recognize the need to construct and test more comprehensive models. The study of distribution channels is progressing from one that has been largely non-analytic, descriptive, and anchored in conventional wisdom to one that is more analytic, rigorous, and employs techniques and approaches from a variety of disciplines. In the years ahead we can expect major contributions as more scholars focus on issues specific to international channels of distribution. Two emerging positions in the literature are information flow and cooperation (cf. Buzzell and Ortmeyer 1995; Mehta et al. 2001; Rosenbloom and Larsen 2003).

The level of sharing of proprietary knowledge in relationships is increasing; the value of such shared information is also increasing. That is, not only is the amount of information exchange growing, but so to is its importance. While e-commerce can certainly be considered a new medium (Cateora and Graham 1999; Cort 1999; Rosenbloom and Larsen 2003), it is the heightened transparency (reduced information asymmetry) among economic actors that is revolutionary. That manufacturer, distributor, and customer can communicate more freely is altering economic behavior and the way in which value is assessed. Presently, in the field of global supply chain management customers can "see" many more suppliers and suppliers can "see" many more customers; this greater breadth has also been accompanied by increased depth. Customers can "see" more deeply into suppliers' value chains and suppliers know more about customers. Such revelations in amount and type of information have fundamentally changed transactions. Some economic principles have not changed; more information is not to 
be equated with better information. Efficiency concerns with information collection and analysis are perhaps more significant in an era in which a plethora of information must be sorted for value at either end of exchange.

Collaboration, cooperation, and alliances seem to be pushing out certain forms of adversarial competition. Recognition that most economic activity takes place in a context - both temporally and among other actors in a network (customers and competitors) - leads to explicit consideration of multi-point games. That options can be held and lost also enters into a firm's calculus. The use of multi-period scenarios is increasingly turned to ensure a viable future. Strategy and strategic positioning is no less important. Ruthlessness has not been eliminated, as much as it has been displaced with insight into alignment of incentives. Buzzell and Ortmeyer (1995) note the extension of relationships, with actors becoming more involved in each other's activities (e.g., joint product development, planning, and promotion). Li and Dant (1997: 209) note that despite greater and asymmetric power, suppliers in an exclusive dealing (ED) channel relationship "adopt a benevolent perspective toward their ED resellers and use their power to enhance the coordination and organization of channel activities, rather than in an opportunistic fashion." $\mathrm{Li}$ (1996) sees channel relationships as dynamic and best approached - either as an academic or practitioner - from a network perspective. Anderson, Day, and Rangan (1997) warn against viewing distribution channels as a peripheral activity; relegating distribution channels to such a position forgoes the opportunity to realize competitive advantage.

\section{REFERENCES}

Anderson, E., Day, G.S., and Rangan, V.K. (1997) Strategic Channel Design. Sloan Management Review, 38(4): 59-69.

Anderson, J.C. and Narus, J.A. (1990) A Model of Distributor Firm and Manufacturer Firm Working Partnerships. Journal of Marketing, 54(1): 42-58.

Assmus, G. and Wiese, C. (1995) How to Address the Gray Market Threat Using Price Coordination. Sloan Management Review, 36(3): 3141.

Aulakh, P.S. and Kotabe, M. (1997) Antecedents and Performance Implications of Channel Integration in Foreign Markets. Journal of International Business Studies, 28(1): $145-175$.

Balabanis, G. (1998) Antecedents of Cooperation, Conflict and Relationship Longevity in an International Trade Intermediary's Supply Chain. Journal of Global Marketing, 12(2): 25-46.

Balabanis, G. (2005) Determinants of Export Intermediaries' ServiceMix Configurations. International Marketing Review, 22(4): 436459.

Bandyopadhyay, S., Robicheau, R.A., and Hill, J.S. (1994) Cross-Cultural Differences in Intrachannel Communications: The United States and India. Journal of International Marketing, 2(3): 83-100. 
Bello, D.C. and Gilliand, D.I. (1997) The Effect of Output Controls, Process Controls and Flexibility on Export Channel Performance. Journal of Marketing, 61(1): 22-38.

Bello, D.C. and Lothia, R. (1995) Export Channel Design: The Use of Foreign Distributors and Agents. Journal of the Academy of Marketing Science, 23(2): 83-93

Bello, D.C., Urban, D.J., and Verhage, B.J. (1991) Evaluating Export Middlemen in Alternative Channel
Bello, D.C., Chelariu, C., and Zhang,

L. (2003) The Antecedents and Performance Consequences of Relationalism in Export Distribution Channels. Journal of Business Research, 56(1): 1-16.

Bergen, M., Heide, J.B., and Dutta, S. (1998) Managing Gray Markets through Tolerance of Violations: A Transaction Cost Perspective. Managerial and Decision Economics, 19(3): 157-165.

Boddewyn, J.J. (1981) Comparative Marketing: The First Twenty-Five Years. Journal of International Business Studies, 12(1): 61-79.

Borin, N., Van Vranken, C., and Farris, P.W. (1991) Research Note: A Pilot Test of Discrimination in the Japanese Distribution System. Journal of Retailing, 67(1): 93106.

Buzzell, R.D. and Ortmeyer, G. (1995) Channel Partnerships Streamline Distribution. Sloan Management Review, 36(3): 85-96.

Cabaniss, R.F. (1991) Perspectives on International Distribution: A Framework for Classifying the Research Agenda. Journal of Global Marketing, 4(4): 3-20.

Cateora, P.R. and Graham, J.L. (1999) International Marketing. 10th edition. Irwin McGraw-Hill. Boston, MA.

Cavusgil, S.T., Deligonul, S., and Zhang, C. (2004) Curbing Foreign Distributor Opportunism: An Examination of Trust, Contracts, and the Legal Environment in International Channel Relationships. Journal of International Marketing, 12(2): 7-27.

Cavusgil, S.T. and Kirpalani, V.H. (1993) Introducing Products into Export Markets: Success Factors. Journal of Business Research, 27(1): $1-15$.

Cavusgil, S.T. and Zou, S. (1994) Marketing Strategy-Performance Relationship: An Investigation of the Empirical Link in Export Market Ventures. Journal of Marketing, 58(1): 1-21.

Chen, H.-L. and Huang, Y. (2004) The Establishment of Global Marketing Strategic Alliances by Small and Medium Enterprises. Small Business Economics, 22(5): 365-377.

Chu, W. (1989) Determinants of Marketing Channels: Extent of Demand, Differential Costs and Entry Threats. Southern Economic Journal, 56(2): 349-362.

Coase, R.H. (1937) The Nature of the Firm. Economica, 4(16): 386-405.

Cort, S.G. (1999) Industrial Distribution: How Goods will go to Market in the Electronic Marketplace. Business Economics, 34(1): 53-55.

Dwyer, F.R. and Oh, S. (1988) A Transaction Cost Perspective on Vertical Contractual Structure 
and Interchannel Competitive Strategies. Journal of Marketing, 52(2): 21-34.

Dwyer, F.R., Schurr, P.H., and Oh, S. (1987) Developing Buyer-Seller Relationships. Journal of Marketing, 5](2): 11-27.

Ekeledo, I. And Sivakumar, K. (1998) Foreign Market Entry Mode Choice of Service Firms: A Contingency Perspective. Journal of the Academy of Marketing Science, 26(4): 274 292.

El-Ansary, A.I. and Stern, L.W. (1972) Power Measurement in the Distribution Channel. Journal of Marketing Research, 9(1): 47-52.

Erramilli, M.K. and Rao, C.P. (1993) Service Firm's International Entry-Mode Choice: A Modified Transaction-Cost Analysis Approach. Journal of Marketing, 57(3): 19-38.

Ford, I.D. (1980) The Development of Buyer-Seller Relationships in Industrial Markets. European Journal of Marketing, 14(5/6): 339-353.

Ford, I.D. and Rosson, P.J. (1982) The Relationship between Export Manufacturers and Their Overseas Distributors, in Czinkota, $M$. R. and Tesar, G. (Eds.), Export Management: An International Context. Praeger Publishers. New York, NY, pp. 47-52.

Fram, E.H. (1992) We Can Do a Better Job of Selecting International Distributors. Journal of Business and Industrial Marketing, 7(2): 61-70.

Frazier, G.L. (1999) Organizing and Managing Channels of Distribution. Journal of the Academy of Marketing Science, 27(2): 226-240.

Frazier, G.L. and Antia, K.D. (1995) Exchange Relationships and
Interfirm Power in Channels of Distribution. Journal of the Academy of Marketing Science, 23(4): $321-326$.

Frazier, G.L., Gill, J.D., and Kale, S.H. (1989) Dealer Dependence Levels and Reciprocal Actions in a Channel of Distribution in a Developing Country. Journal of Marketing, 3(1): 50-69.

Frazier, G.L. and Kale, S.H. (1989) Manufacturer-Distributor Relationships: A Sellers' Versus Buyers' Market Perspective. International Marketing Review, 6(6): 7-26.

Gadde, L.-K. (1993) Evolution Processes in Distribution Networks. Advances in International Marketing, 5: 43-56.

Ganesan, S. (1993) Negotiation Strategies and the Nature of Channel Relationships. Journal of Marketing Research, 30(2): 183-203.

Ganesan, S. (1994) Determinants of Long-Term Orientation in BuyerSeller Relationships. Journal of Marketing, 58(2): 1-19.

Gaski, J.F. (1984) The Theory of Power and Conflict in Channels of Distribution. Journal of Marketing, 48(3): 9-24.

Geyskens, I., Steenkamp, J.-B.E.M., Scheer, L.K., and Kumar, N. (1996) The Effects of Trust and Interdependence on Relationship Commitment: A Trans-Atlantic Study. International Journal of Research in Marketing, 13(4): 303-317.

Griffith, D.A. and Ryans Jr., J.K. (1995) Strategically Employing Natural Channels in an Era of Global Marketing. Journal of Marketing Practice, 1(4): 52-69.

Griffith, D.A., Chandra, A., and Fealey, T. (2005) Strategically Employing 
Natural Channels in an Emerging Market. Thunderbird International Business Review, 47(3): 287-311. Grunert, K.G., Jeppesen, L.F., Jespersen, K.R., Sonne, A.-M., Hansen, K., Tronsen, T., and Young, J.A. (2005) Market Orientation of Value Chains: A Conceptual Framework based on Four Case Studies from the Food

Harvey, M. and Novicevic, M.M.

(2002) Selecting Marketing Managers to Effectively Control Global Channels of Distribution. International Marketing Review, 19(5): 525-544.

Heide, J. (1994) Interorganizational Governance in Marketing Channels. Journal of Marketing, 58(1): 7185.

Heide, J. and John, G. (1988) The Role of Dependence Balancing in Safeguarding Transaction-Specific Assets in Conventional Channels. Journal of Marketing, 52(1): 2035.

Heide, J. and John, G. (1990) Alliances in Industrial Purchasing: The Determinants of Joint Action in Buyer-Supplier Relationships. Journal of Marketing Research, 27(1): 24-36.

Heide, J.B. and John, G. (1992) Do Norms Matter in Marketing Relationships? Journal of Marketing, 56(2): 3244.

(1)

Howard, D.G. and Maskulka, J.M. (1988) Will American Export Trading Companies Replace Traditional Export Management Companies? International Marketing Review. 5(4): 41-50.

Hunt, S. and Nevin, J. (1974) Power in a Channel of Distribution: Sources and Consequences. Journal of Marketing Research, 11(2): 186193.

Hill, C.W.L., Hwang, P., and Kim, W.C. (1990) An Eclectic Theory of the Choice of International Entry Mode. Strategic Management Journal, 11(2): 117-128.

Hofstede, G. (1984) Culture's Consequences: International Differences in Work-Related Values. Sage Publications. Beverly Hills, CA.
Johnson, J.L., Sakano, T., Cote, J.A., and Onzo, N. (1993) The Exercise of Interfirm Power and Its Repercussions in U.S.-Japanese Channel Relationships. Journal of Marketing, 57(2): 1-10.

Johnson, J.L., Sakano, T., and Onzo, N. (1990) Behavioral Relations in Across-Culture Distribution Systems: Influence, Control, and Conflict in U.S.-Japanese Marketing Channels. Journal of International Business Studies, 2l(4): 639-655.

Kale, S.H. and McIntyre, R.P. (1991) Distribution Channel Relationships in Diverse Cultures. International Marketing Review, 8(3): 31-45.

Karunaratna, A.R. and Johnson, L.W. (1997) Initiating and Maintaining Export Channel Intermediary Relationships. Journal of International Marketing, 5(2): 11-32.

Katsikeas, C.S. and Piercy, N.F. (1991) The Relationship between Exporters from a Developing Country and Importers Based in a Developed Country: Conflict Considerations. European Journal of Marketing, 25(1): 6-25.

Keitt Jr., J.K., (1990) Pitfalls and Promises of Foreign Distributors. Management Review, 79(5): 1619.

Kim, J. (2001) Distribution Channel Selection of Foreign-Owned Firms 
in the Korean Market: Combining the Transactions Cost Approach and the Functional Approach. Journal of Global Marketing Channels, 8(3/4): 49-64.

Kim, J. and Daniels, J.D. (1991) Marketing Channel Decisions of Foreign Manufacturing Subsidiaries in the U.S.: The Case of the Metal and Machinery Industries. Management International Review, 31(2): 123138.

Kim, K. and Oh, C. (2002) On Distributor Commmitment in Marketing Channels for Industrial Products: Contrast between the United States and Japan. Journal of International Marketing, 10(1): 72-97.

Kim, L., Nugent, J.B., and Yhee, S.J. (1997) Transaction Costs and Export Channels of Small and Medium-Sized Enterprises: The Case of Korea. Contemporary Economic Policy, 15(1): 104-120.

Kim, S.K. (2003) A Cross-National Study of Interdependence Structure and Distributor Attitudes: The Moderating Effect of Group Orientation. International Journal of Research in Marketing, 20(2): 193-214.

Klein, S. (1991) Selection of International Marketing Channels. Journal of Global Marketing, 4(4): 21-37.

Klein, S., Frazier, G.L., and Roth, V.J. (1990)A Transaction Cost Analysis Model of Channel Integration in International Markets. Journal of Marketing Research, 27(2): 196- 208.

Klein, S. and Roth, V.J. (1990) Determinants of Export Channel Structure: The Effects of Experience and Psychic Distance Reconsidered. International Marketing Review, $7(5): 27-38$.

Klein, S. and Roth, V.J. (1993)
Satisfaction with International Marketing Channels. Journal of the Academy of Marketing Science, 21(1): 39-44.

Leonidou, L.C. (1989) Behavioral Aspects of the Exporter-Importer Relationship: The Case of Cypriot Exporters and British Importers. European Journal of Marketing, 23(7): 17-33.

Li, D. and Dant, R.P. (1997) An Exploratory Study of Exclusive Dealing in Channel Relationships. Journal of the Academy of Marketing Science, 25(3): 201-213.

Li, Z. (1996) The Dynamics of Export Channels from the United Kingdom to the People's Republic of China: A Network Approach. Avebury Press. Aldershot, UK.

Liu, H. and Wang, Y.P. (1999) Coordination of International Channel Relationships: Four Case Studies in the Food Industry in China. Journal of Business \& Industrial Marketing, 14(2): 130-150.

Llanes, V.A. and Melgar, I.E. (1993) Antecedents of Export Channel Relationships between Exporters from a Developing Country and Foreign Importers. Multinational Business Review, 1(1): 27-37.

Long, D.C. (2003) International Logistics: Global Supply Chain Management. Kluwer Academic Publishers. Boston, MA.

Madhok, A. and Tallman, S.B. (1998) Resources, Transactions and Rents: Managing Value through Interfirm Collaborative Relationships. Organization Science, 9(3): 326339.

Marshall, R.S. (2003) Building Trust Early: The Influence of First and Second Order Expectations on Trust in International Channels of Distribution. International Business 
Review, 12(4): 421-443.

Mazzoleni, R. (1998) The Agency System. in the International Distribution of U.S. Machine Tools, 19001915: Social Norms and Contracts.
Business and Economic History, 27(2): 420-430.

McNaughton, R.B. (2002) The Use of Multiple Export Channels by

\section{Michael, J. (1998) A Supplemental}

Distribution Channel? The Case of U.S. Parallel Export Channels. Multinational Business Review, 6(1): 24-35.

Morgan, R.M. and Hunt, S.D. (1994) The Commitment-Trust Theory of Relationship Marketing. Journal of Marketing, 58(3): 20-38.
Moore, R.A. (1991) Relationship States in an International Marketing Channel. European Journal of Marketing, 25(5): 47-59.

Moore, R.A. (1992) A Profile of UK Manufacturers and West German Agents and Distributors. European Journal of Marketing, 26(1): 41-51.

Myers, M. (1999) Incidents of Gray Market Activity among U.S. Exporters: Occurrences, Characteristics, and Consequences. Journal of International Business Studies, 30(1): $105-126$.

Myers, M.B. and Harvey, M. (2001) The Value of Pricing Control in Export Channels: A Governance Perspective. Journal of International Marketing, 9(4): 1-29.

Osborne, K. (1996) The Channel Integration Decision for Small- to Medium-Sized Manufacturing Exporters. International Small Business Journal, 14(3): 40-56.

Paswan, A.K. and Young, J.A. (1999) An Exploratory Examination of the Relationship between Channel Support Mechanisms and Relational Norms in an International Context. Journal of Business \& Industrial Marketing, 14(5/6): 445-455.

Ramaseshan, B. and Patton, M.A. (1994) Factors Influencing International Channel Choice of Small Business Exporters. International Marketing Review, 11(4): 19-34.

Rialp, A., Axinn, C., and Thach, S. 2002. Exploring Channel Internationalization among Spanish Exporters. International Marketing Review. 19(2): 133-155.

Rose, G.M. and Shoham, A. 2004. Interorganizational Task and Emotional Conflict with International Channels of Distribution. Journal of Business Research. 57(9): 942950. 
Rosenbloom, B. (1990) Motivating Your International Channel Partners. Business Horizons, 33(2): 53-57.

Rosenbloom, B. (1999) Marketing Channels: A Management View. 6th edition. Dryden Press. Fort Worth, TX.

Rosenbloom, B. and Larsen, T.L. (1991) International Channels of Distribution and the Role of Comparative Marketing Analysis. Journal of Global Marketing, 4(4): $39-54$.

Rosenbloom, B. and Larsen, T. (2003)

Communication in International Business-to-Business Marketing Channels: Does Culture Matter? Industrial Marketing Management, 32(4): 309-315.

Rosson, P.J. and Ford, I.D. (1980)

Stake, Conflict and Performance in Export Marketing Channels. Management International Review, 20(4): 31-37.

Samiee, S. (1993) Retailing and Channel

Considerations in Developing Countries: A Review and Research Propositions. Journal of Business Research, 27(2): 103-130.

Seifert, B. and Ford, J. (1989) Export Distribution Channels. Columbia Journal of World Business, 24(2): 15-22.

Shin, C., Hahn, M., and Park, S. (1996) Competitive Intensity and Channel Structure in Korean Consumer Goods Industries. Advances in International Marketing, 7: 63-81. Shipley, D., Cook, D., and Barnett, E. (1989) Recruitment, Motivation, Training and Evaluation of Overseas Distributors. European Journal of Marketing, 23(2): 79-93.

Shoham, A., Rose G. M., and Kropp, F. (1997) Conflict in International Channels of Distribution. Journal of Global Marketing, I1(2): 5-22.
Shoham, A., Rose G.M., and Kropp, F. (1999) International Channels of Distribution: The Role of Centralization. Journal of Global Marketing, 13(1): 87-104.

Stern, L.W. (1969) Distribution Channels: Behavioral Dimensions. Houghton Mifflin. Boston, MA.

Stern, L.W. and El-Ansary, A.I. (1992) Marketing Channels, 4th edition, Prentice Hall, Englewood Cliffs, NJ.

Stern, L.W. and Reve, T. (1980) Distribution Channels as Political Economies: A Framework for Comparative Analysis. Journal of Marketing, 44(3): 52-64.

Terpstra, V. and Yu, C.J. (1990) Piggybacking: A Quick Road to Internationalization. International Marketing Review, 7(4): 52-63.

Thomas, A.R. and Wilkinson, T.J. (2005) It's the Distribution Stupid! Business Horizons, 48(2): 125-134.

Weigand, R.E. (1989) The Gray Market Comes to Japan. Columbia Journal of World Business, 24(3): 18-24.

Weigand, R.E. (1991) Parallel Import Channels: Options for Preserving Territorial Integrity. Columbia Journal of World Business, 26(1): 53-60.

Welch, C. and Wilkinson 1. (2005) Network Perspectives on Interfirm Conflict: Reassessing a Critical Case in International Business. Journal of Business Research, 58(2): 205-213.

Williamson, O.E. (1979) TransactionCost Economics: The Governance of Contractual Relations. Journal of Law and Economics, 22(3): 3-61.

Williamson, O.E. (1981) The Economics of Organization: The Transaction Cost Approach. American Journal of Sociology, 87(3): 548-577.

Yavas, U. (1998) The Bases of Power 
in International Channels. International Marketing Review, 15(2): 140-150.

Yoon, H.D., Morash, E.A., Cooper, M.B., and Clinton, S.R. (1996)

3 Global Comparisons of Channel

$\boldsymbol{D}$ Integration Strategies and Strategic

- Alliances. Advances in International Marketing, 7: 3-20.

(1) Zhang, C., Cavusgil, S.T., and Roath, A.S. $\propto$ (2003) Manufacturer Governance of Foreign Distributor Relationships:

(s) Do Relational Norms Enhance

( Competitiveness in the Export

(U) Market? Journal of International

$\subsetneq \quad$ Business Studies, 34(6): 550-566.

כ

$\infty$

চ

E

0

$\mp$

ro

$\frac{5}{ \pm}$

()

上 